\title{
HAVAINTOJA PIHATOISTA KYLMILLÄ SEUDUILLA
}

\author{
ERKKI H. OKSANEN
}

Helsingin Yliopiston maanviljelystaloudellinen laitos, Rukkila, Helsinki

Saapunut 30.4. 1953

Maanviljelytavat ovat muuttuneet suuresti viimeisen kahdenkymmenen vuoden aikana. Maatalouden koneellistaminen on osaltaan tehnyt mahdolliseksi suuremman tuotannon saavuttamisen entistä vähemmällä työllä. Karjataloudessa kuitenkin työ- ja rakennuskustannukset nostavat maidon hintaa korkeammaksi kuin mitä kuluttajaväestö on halukas maksamaan. Eräs näiden kustannuksien alentaja on ns. pihatto (= karsinanavetta).

Pihattotyypin karjasuojalla on monia etuisuuksia, kuten pieni työnmenekki, halvahko rakenne, lehmien liikkumavapaus, ruokinta- ja lypsytyön keveneminen, lehmien terveydentilan paraneminen ja saatavan lannan hyvä laatu ja suuri määrä. Eräs pahimmista haitoista on suuri kuivikemenekki, mikä etenkin Pohjois-Euroopassa rajoittaa mainitun navettatyypin käyttöä. On myös väitetty heinänkulutuksen lisääntyvän suuresti, ja lehmien kärsivän kylmyydestä, tuotannon vähenevän jne. Näistä seikoista on suoritettu tutkimuksia etenkin U.S.A:ssa.

Wisconsin Yliopiston East Hill-maatilalla teräsrakenteisissa koenavetoissa suoritetut tutkimukset (6) vv. 1941-1951 ovat osoittaneet kylmän pihaton soveliaaksi karjasuojaksi runsastuottoisillekin karjoille. Navettatyypillä ei ole ollut mitään vaikutusta tuotetun maidon määrään tai laatuun, sillä parsinavetan ja pihaton lehmistä saatiin samat tuotokset. Pihatossa pidettyjen lehmien terveydentila oli hieman parempi kuin parsinavetassa olleiden. Karkearehujen kulutus oli pihatoissa $3-6 \%$ suurempi, mutta tämän korvannee lehmien vastaavasti suurempi painonlisäys talviruokintakauden aikana.

Kuivikemenekki oli pihatossa tutkimuksen alkuvuosina lähes kolminkertainen parsinavetan määrään verraten, mutta hoitotapojen kehityttyä ainoastaan n. $10 \%$ suurempi viimeisenä koevuonna. Työnkäyttö oli tutkimuskauden lopulla pihatossa $35 \%$ pienempi kuin parsinavetassa.

Vaikka lämpötila kylmän pihaton sisällä laski usein - 20 asteeseen kylmimmän mitatun sisälämpötilan oltua $-30.6^{\circ} \mathrm{C}$ ja ulkolämpötilan $-38.3^{\circ} \mathrm{C}$, ei kylmyydellä havaittu olevan mitään epäedullista vaikutusta maidontuotantoon. Palava lanta makuualueella muodosti lehmille lämpimän makuualustan. 
Lämminseinäinen pihatto osoittautui epätyydyttäväksi ratkaisuksi jo yksinomaan siitäkin syystä, että kosteuden tiivistyminen teki makuualueen jatkuvasti märäksi, mitä epäkohtaa ei edes lisätyllä kuivikkeiden käytöllä saatu autettua. Lisäksi esiintyi lämpimässä pihatossa pahoja hajuja. Lehmillä ei myös ollut jatkuvaa jaloittelumahdollisuutta ulkotarhassa.

DicE (3) esittää havaintojen ja tutkimusaineiston todistavan, että lehmät kestävät hyvin alhaisia lämpötiloja Pohjois-Dakotan kylmässä ja kuivarsa ilmastossa. Jos lehmiä ruokitaan kunnolla ja niillä on suoja tuulta ja lumi- tai vesisadetta vastaan sekä kuiva makuupaikka, tuottavat ne aivan yhtä hyvin pihatossa kuin parsinavetassakin. Havaintojen mukaan lehmät mielellään viipyivät ulkona sangen kylmilläkin säillä, mitkä eivät olleet haitanneet niitä lainkaan. Niinpä joulukuun 1926 keskilämpötila oli $-13^{\circ} \mathrm{C}$ vaihtelurajojen ollessa $-30^{\circ}-+2^{\circ}$. Kuivikkeenkulutus oli tämän tutkimuksen mukaan ollut pihatossa n. 1/3 parsinavetan määrää suurempi.

Michigan State College Special Bulletinin 363 (1) mukaan on kuivikemenekki kylmissä pihatoissa $3.6-6.8 \mathrm{~kg}$ ja parsinavetassa $2.3-3.6 \mathrm{~kg}$ päivässä lehmää kohden. Samassa esityksessä suositellaan sellaista rakennetta, jossa kylmän pihaton ovet avautuvat etelään tai itään, ja ainakin yhden oven tulisi olla jatkuvasti avoinna.

Saman käsityksen esittävät CLEAver ja CARTER (2), mutta kuivikemenekki ei heidän mukaansa ole pihatossa suurempi kuin parsinavetassakaan edellyttäen, että pihatto on asianmukaisesti rakennettu ja hoidettu.

Pohjois-Europassa on pihattoja käytössä vähäisessä määrin. Nämä ovat kuitenkin lähes yksinomaan lämminseinäistä tyyppiä. Hännisen (4) mukaan heinänkulutus on n. $75 \%$ ja kuivikkeenkulutus $80-150 \%$ suurempi pihatossa kuin parsinavetassa. Lehmät on laskettava ulos jaloittelemaan, mutta ovien jatkuvaa aukipitoa ei suositella.

Kirjoittaja suoritti kesällä 1952 tutkimuksen (5), joka käsitti 19 pohjois-Michiganin pihattoa. Sikäläiset olosuhteet vastaavat lähinnä meillä lounais- ja eteläSuomessa vallitsevia. Lunta saattaa olla talvisaikaan yli metrin vahvuudelta eivätkä pakkasaallot, jolloin lämpötila voi pysytellä parikin viikkoa $-25^{\circ}$ vaiheilla, ole kovin harvinaisia. Tutkimuskohteina olleilla tiloilla muistuttivat viljelytavatkin suomalaisia, mm. useimmilla tiloilla vilja leikattiin sitovilla leikkuukoneilla ja pellollakuivatuksen jälkeen puitiin puimakoneilla. Kaikilla tutkimustiloilla oli traktori, johon kiinnitettävällä lannankuormaajalla suoritettiin pihaton tyhjennys lannasta. Lannan pellollelevityksessä käytettiin lannanlevittäjää. Lehmien lypsy suoritettiin kesäaikanakin pihaton lypsyhuoneessa, koska laitumet olivat talouskeskuksen välittömässä ympäristössä.

Tutkimustiloilla olivat pihatot olleet käytännössä $1 / 2-15$ vuotta. - Tutkimuksessa keskityttiin kysymyksiin, joita suomalainen maanviljelijä pitää arveluttavina tekijöinä pihattojärjestelmässä, nim. kovan kylmyyden vaikutuksen lehmiin sekä kuivikkeiden ja heinien suureen kulutukseen. Näiden seikkojen ohella on huomioitu mm. rakennustapa, rakenteelliset ym. laitteet ja karjanhoitotöiden järjestely. Tutkimusaineisto saatiin haastattelemalla maanviljelijöitä. Liitteinä on valokuvia ja pohjapiirros kustakin pihatosta. 


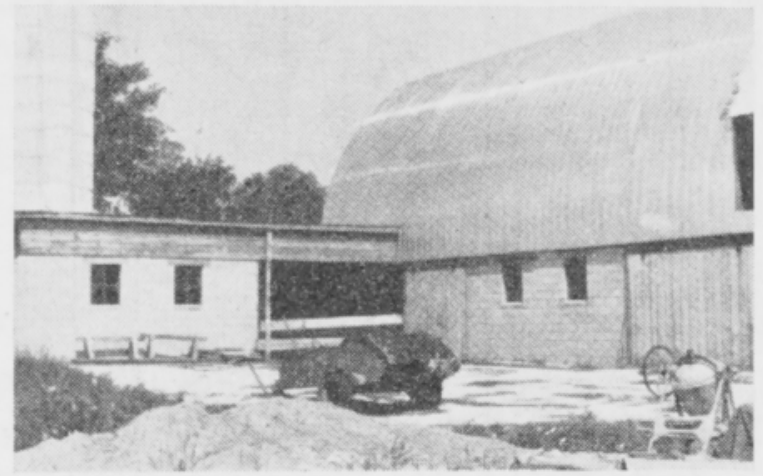

Kuva 1.

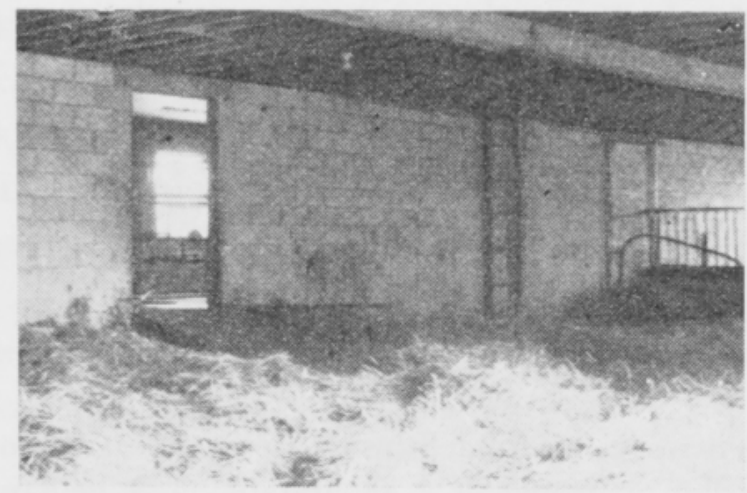

Kuva 3.

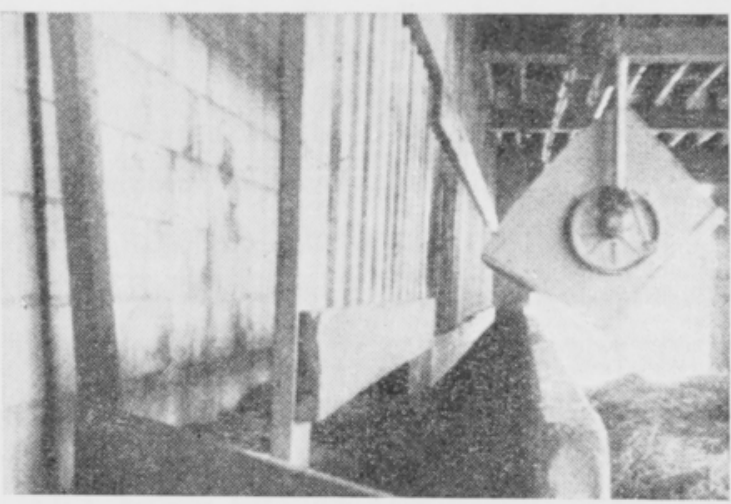

Kuva 2.

Kuvat $1-3$. Mr. Pat W. Hawkins'in pihatto. 1) Länsisivusta ja ruokinta-alueen siipirakennus, etualalla kestopäällystetty jaloittelualue. 2) Ruokintapöytä, jonka etuosan yläpuolella säilörehuvaunun rata. Väliseinän taa pudotetaan heinät n. kahdesti viikossa. 3) Osa makuualueesta. Lypsyhuoneesta alueelle johtava ovi avoin. Oviaukon oikealla puolella juoma-allas.

Kuvat n:o $1-5$ esittävät eräitä tutkimuskohteita ja piirrokset n:o $1-2$ kahden parhaan pihaton pohjapiirrosta. Piirroksista käy ilmi tyypillisen pihaton eri alueet: makuu-, ruokinta-, jaloittelu- ja lypsyalue sekä maitohuone.

Muutamissa tutkimuskohteina olleissa pihatoissa oli mainittujen alueiden keskinäinen järjestely epäonnistunut aika pahasti, josta johtuen pihatto ei vastannut kaikkia sille pantuja odotuksia. Siitä huolimatta ei näilläkään tiloilla oltu vakavasti ajateltu siirtymistä takaisin parsinavettaan. Yhteisen toteamuksen mukaan lehmät viihtyivät pihatossa irrallaan niin hyvin, ettei niitä olisi hennonut mitenkään panna kytkyihin. Pihattojen muutkin edut tulivat haastattelujen aikana selvästi esille.

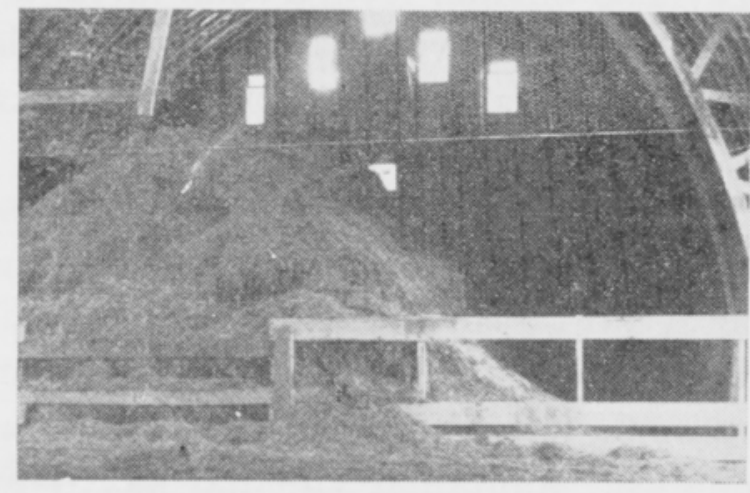

Kuva 4. Mr. Harold Stinson'in heinälato, joka yhtyy välittömästi pihaton makuualueeseen.

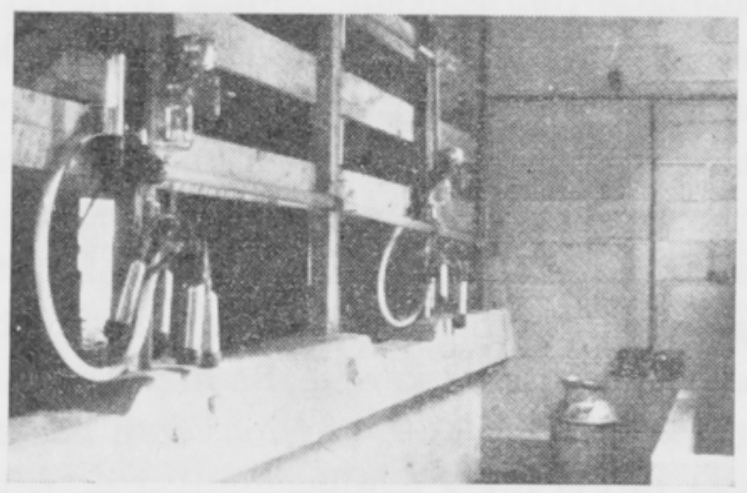

Kuva 5. Mr. Coors'in yksinkertainen lypsymaitohuoneratkaisu. Maito menee suoraan lypsylaitteesta jäähdytysaltaassa (kuvan oikeassa alanurkassa) olevaan pystöön. 

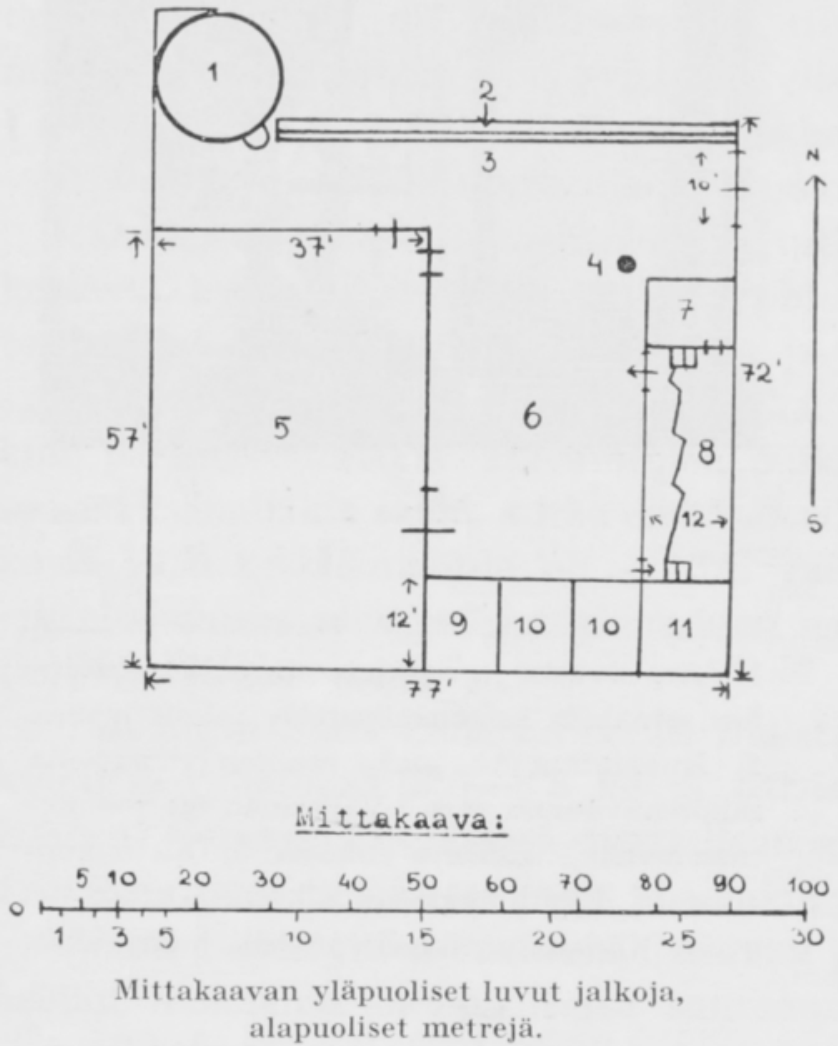

Piirros 1. Pat W. Hawkins'in pihatto. 1. Säilörehutorni, 2. ruokintapöytä, 3 . ruokinta-alue, 4 . juomakuppi, 5. kestopäällystetty jaloittelualue, 6. makuualue, 7. väkirehukoppi, 8. lypsyhuone parsineen, 9. sonnin karsina, 10. vasikka- ja poikimiskarsinat, 11. maitohuone.

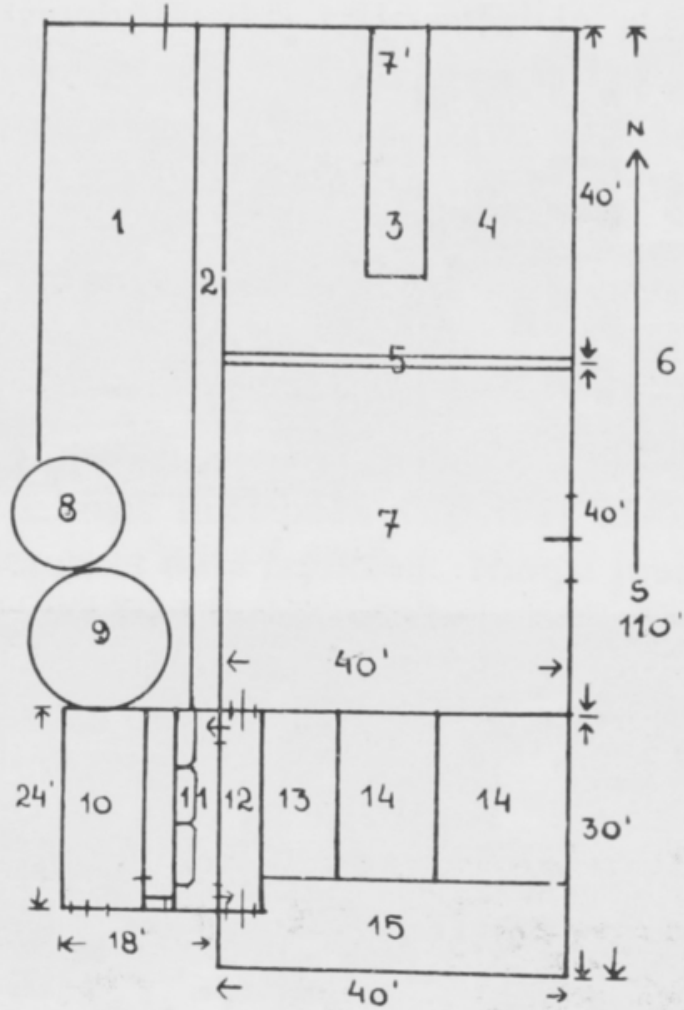

Piirros 2. Harold Stinsonin pihatto. 1. Säilörehun syöttöhuone, 2 . ruokintapöytä, 3 . heinänkuivaajan kanava, 4. heinälato, 5. siirrettävä heinän syöttöaitaus, 6. jaloittelupiha, 7. makuualue, 8. heinäsäilörehun torni, 9. maissisäilörehun torni, 10. maitohuone, 11. lypsyhuone parsineen, 12. pidätyskarsina, 13. sonnin karsina, 14. nuoren karjan karsinat, 15. vasikkaja poikimiskarsinat.

Tutkimuksessa päädyttiin seuraaviin tuloksiin:

1) Sään kylmyys ei ole vaivannut lehmiä pihatoissa, vaikka ainakin yksi ovi on pidetty kovimmillakin pakkasilla auki. Lämpötila voi laskea $-30^{\circ}$, mutta auringon tullessa esille lehmät menevät ulos tyynellä ilmalla. Kylmä tuuli tai räntäsade ajaa lehmät sisälle. Lehmien makuualueen on oltava vedolta suojattu. Siellä ne voivat paneutua lämpöiselle, palavan lannan muodostamalle makuualueelle, joka on lämpimämpi ja pehmeämpi kuin kuivitettu parsi.

2) Kuivikemenekki on vaihdellut suuresti; n. 30-200\% enemmän kuin vastavan kokoisessa parsinavetassa. Pihaton sisustus, eri alueiden keskinäinen sijoitus ja karjan hoitotavat ovat vaikuttaneet ratkaisevasti tässä suhteessa. Asianmukaisella järjestelyllä ja oikealla hoitotavalla saadaan kuivikemenekki supistumaan niin, että se on 30-50\% parsinavetan määrää suurempi. Silputut oljet ovat osoittautuneet pitkiä olkia edullisemmiksi ja riittoisammiksi. Muutamat viljelijät käyttivät lisäksi sahajauhoja esittäen, että siten saadaan tasainen ja tukeva alusta, jolla lehmien ja ihmistenkin on mukava kävellä.

3) Eläinten heinänkulutus on pihatossa jonkin verran suurempi kuin parsi- 
navettojen, mutta korvauksena tästä on hieman vähentynyt väkirehujen käyttö ja lehmien lihominen talviruokintakaudella.

Pihaton käyttö karjasuojaksi myös suhteellisen kylmän ilmanalan seuduilla on täysin mahdollista. Pihaton eri alueiden keskinäinen järjestely ja karjan hoitotavat ratkaisevat, kuinka hyvin ko. karjasuojan käytössä onnistutaan.

Suomen olosuhteisiin ei voitane suositella kylmää pihattoa, ainakaan ennenkuin ko. rakenteesta on saatu riittävästi kokemusta. Sensijaan ns. puolikylmällä pihatolla voisi meilläkin olla menestymisen mahdollisuudet. Tällaisessa rakennuksessa saavat seinät ja välikatto olla suhteellisen kevytrakenteiset, mutta tiiviit. Ovet sulkien saadaan lämpötila pihaton sisäpuolella pysymään ulkoilman lämpötilaa huomattavasti korkeampana, mikä lienee meillä välttämätöntä pitkinä pakkaskausina. Tällöinkin on lehmien päästävä ulos jaloittelemaan mikäli haluavat. Karkea- ja tuorerehun sisäruokintamahdollisuus täytyy varata kylmintä talvikautta varten, mutta syksyllä ja keväällä ko. rehujen syöttö voi tapahtua ulkosalla amerikkalaisen tavan mukaan, tai erikoisessa syöttökatoksessa, kuten oheisten piirrosten esittämissä tapauksissa.

Pyrittäessä tuottamaan maitoa entistä taloudellisemmin on syytä harkita pihaton käytäntöönottoa työ- ja rakennuskustannuksien alentamisen sekä muiden ko. järjestelmän etujen vuoksi.

KIR JALLISUUTTA

(1) Brown, I. H., Cargill, B. F. ja Bookhout, B. R. 1950. Pen-Type Dairy Barns. Michigan State College, Agr. Exp, Sta., Special Bull. 363, p. 1-11.

(2) Cleaver, Thayer ja Carter, Deane G. 1952. Loose Housing for the Farm Dairy. University of Illinois, College of Agr., Circular 694, p. 3.

(3) Dice, James R. 1947. Some Effects of Types of Shelter Upon Dairy Cattle. North Dakota Agricultural College. Agr. Exp. Sta. Bull. 344, p. 4-18.

(4) Hänninen, TAuno. 1951. Suomalaisen lämminseinäisen karsinanavetan ominaisuuksista ja käytöstä. Keski-Suomen Maanviljelysseura, p. $2-4$.

(5) Oksanen, Erkкi H. 1952. Loose Housing Barns in Cold Regions. Michigan State College. Agricultural Engineering Department, p. $1-22$.

(6) Witzel, S. A. ja Derber, D. W. 1952. Engineering Phases of Dairy Barn Research, $1941-1951$. Agricultural Engineering, p. $635-642$.

SUMMARY:

OBSERVATIONS ON LOOSE HOUSING BARNS IN COLD REGIONS

ERKKI H. OKSANEN

Department of Agricultural Economics, University of Helsinki

Production efficiency in dairy cattle farming has been raised by the use of loose housing barns. However, there have been many arguments over its suitability for the cold regions of the U.S.A. and Europe. 
Bedding requirement and hay consumption are greater in a loose housing barn than in a stanchion barn. Moreover, it has been claimed that cows will suffer from subzero weather. Visits and interviews at nineteen North Michigan loose housing barn farms proved the last-mentioned argument to be wrong, since cold weather had never caused any trouble. The bedded area must be protected from draught. Wind and wet snow are wores than cold weather.

In properly arranged loose housing barns bedding consumption has been 30 to 50 per cent more than in stanchion barns. On some farms the bedding requirement has been three times the amount needed for stanchion barns.

Hay consumption has been somewhat more than in a stanchion barn.

Loose housing barns can be successfully operated in relatively cold regions. Barn arrangement and operation practices determine the degree of success. Where a proper loose housing barn can be constructed and it is properly operated the advantages of the system far outweigh the disadvantages. 